\title{
Why cuckoos should parasitize parrotbills by laying eggs randomly rather than laying eggs matching the egg appearance of parrotbill hosts?
}

\author{
Canchao Yang ${ }^{1}$, Fugo Takasu², Wei Liang ${ }^{1 *}$ and Anders P Møller ${ }^{3}$
}

\begin{abstract}
The coevolutionary interaction between cuckoos and their hosts has been studied for a long time, but to date some puzzles still remain unsolved. Whether cuckoos parasitize their hosts by laying eggs randomly or matching the egg morphs of their hosts is one of the mysteries of the cuckoo problem. Scientists tend to believe that cuckoos lay eggs matching the appearance of host eggs due to selection caused by the ability of the hosts to recognize their own eggs. In this paper, we first review previous empirical studies to test this mystery and found no studies have provided direct evidence of cuckoos choosing to parasitize host nests where egg color and pattern match. We then present examples of unmatched cuckoo eggs in host nests and key life history traits of cuckoos, e.g. secretive behavior and rapid egg-laying and link them to cuckoo egg laying behavior. Finally we develop a conceptual model to demonstrate the egg laying behaviour of cuckoos and propose an empirical test that can provide direct evidence of the egg-laying properties of female cuckoos. We speculate that the degree of egg matching between cuckoo eggs and those of the host as detected by humans is caused by the ability of the hosts to recognize their own eggs, rather than the selection of matching host eggs by cuckoos. The case of Common Cuckoos (Cuculus canorus) and their parrotbill hosts (Paradoxornis alphonsianus), where it has been shown that both have evolved polymorphic eggs (mainly blue and white), was used to develop a conceptual model to demonstrate why cuckoos should utilize parrotbill hosts by laying eggs randomly rather than laying eggs matching the appearance of host eggs.

In conclusion, we found no evidence for the hypothesis that cuckoos lay eggs based on own egg color matching that of the parrotbill-cuckoo system. We argue theoretically that laying eggs matching those of the hosts in this system violates a key trait of the life history of cuckoos and therefore should be maladaptive.
\end{abstract}

Keywords: Host imprint, Egg laying behavior, Egg color, Host selection, Common cuckoo, Egg polymorphy

\section{Introduction}

The well-known arms race Between parasitic cuckoos and their hosts has long been a model system for the study of coevolution and microevolution (Davies, 2000; Soler, 2014). Approximately 2300 years ago, Aristotle (382-322 BC) wrote that "it (i.e., the Common Cuckoo Cuculus canorus) lays its eggs in the nest of smaller birds after devouring these birds's eggs" (Peck 1970). Many years later, the 'father of vaccination', Edward Jenner (1788), observed the ejection behavior of cuckoo chicks and published his finding, on the basis of which he came

\footnotetext{
* Correspondence: liangwei@hainnu.edu.cn

'Ministry of Education Key Laboratory for Tropical Plant and Animal Ecology, College of Life Sciences, Hainan Normal University, Haikou 571158, China Full list of author information is available at the end of the article
}

to be elected a Fellow of the Royal Society. Afterwards Darwin (1859) proposed the first explanation for how the parasitic behavior of cuckoos could have evolved by natural selection. Cuckoos exploit their hosts by transferring parental care to the host and this parasitism is undoubtedly costly for the hosts of the cuckoo (Rothstein and Robinson 1998; Davies 2000; Soler 2014). Furthermore, cuckoo parasitism destroys or severely reduces the reproductive success of its hosts (Davies 2011). This special behavior has provoked evolution of anti-parasitic defences in hosts, mainly involving a specific aggressive response towards cuckoos, a recognition of cuckoo eggs or chicks, a counter-adaptation against cuckoo trickery (e.g., egg mimicry) or fine tuning of parasitic adaptations (e.g., rapid egg-laying) (Dawkins and Krebs 1979; Davies 
2011). Although this coevolutionary interaction between cuckoos and their hosts has been studied for a long time and a series of theories and hypotheses have been proposed, such as evolutionary lag, evolutionary equilibrium, strong eggshell and rapid laying of eggs by parasites, interaction between egg mimicry and egg recognition, host imprinting, host shift and chick recognition (Brooke and Davies 1988; Moksnes et al. 1991; Davies 2000; Røskaft et al. 2002; Langmore et al. 2003; Kilner 2006; Yang et al. 2013a), so far some puzzles have remained unsolved. For example, the question of whether cuckoos parasitize their hosts by laying eggs randomly or matching the egg morphs in host nests is one of the mysteries of the cuckoo problem (Davies 2000, Antonov et al. 2012).

To date four empirical papers have been published to test this mystery (Avilés et al. 2006, Cherry et al. 2007, Antonov et al. 2012, Honza et al. 2014; Table 1), but only one showed that cuckoos lay eggs randomly in the nests of their hosts (Antonov et al. 2012). Scientists tend to believe that cuckoos lay eggs matching the appearance of host eggs due to selection caused by a high egg recognition ability of the hosts (Avilés et al. 2006; Cherry et al. 2007; Honza et al. 2014).

\section{Methods}

At first, we briefly review previous empirical studies which have examined this mystery, provide examples of unmatched cuckoo eggs in host nests and key life history traits of cuckoos, e.g. their secretive behavior and rapid egg-laying and link them to cuckoo egg laying behavior. We then develop a conceptual model to demonstrate why cuckoos should utilize their hosts by laying eggs randomly rather than matching the appearance of host eggs. We opted for coevolution between Common Cuckoos and their parrotbill hosts (Paradoxornis alphonsianus), both of which have evolved polymorphic eggs (mainly blue and white) (Yang et al. 2010, 2013b), as an example for the model and follow with a discussion of this issue. In the end, we propose an empirical test that can provide direct evidence concerning the egg-laying properties of female cuckoos.

\section{Review}

Examples of cuckoo laying of unmatched eggs in host nests It has been supposed that cuckoo nestlings imprint on their foster parents and return to parasitize them as adults (Lack 1968; Davies 2000); however, laying a matching egg is not necessary. According to previous studies, cuckoos lay non-mimetic eggs in nests of many regular hosts (Payne 2005; Lee 2008; Yang et al. 2012a, 2012b; Lowther 2013). For example, Lee (2008) found that the Common Cuckoo laid $52.6 \%$ of unmatched cuckoo eggs in the nests of the Vinous-throated Parrotbill (Paradoxornis webbianus) that lays polymorphic eggs. This percentage is a considerable underestimation because the hosts rejected $82.6 \%$ of poorly-matching eggs and $16.7 \%$ of wellmatching eggs (Lee 2008) and hence many unmatched cuckoo eggs should have been rejected before their detection by observers. Furthermore, cuckoos laid 100\% non-matching eggs in Dunnock (Prunella modularis) nests (Davies and Brooke 1989). Since cuckoos do not experience the responses to their eggs by hosts as dunnocks do, nor recognize unmatched eggs (i.e., accept or reject cuckoo eggs), they should not lay non-mimetic eggs in dunnock nests, if cuckoos were to lay eggs based on their own egg appearance.

\section{Previous studies and their deficiencies}

The first tentative study considering cuckoo-host egg matching was by Avilés et al. (2006), which is a summary of the temporal changes in the degree of matching between Common Cuckoo and host (Acrocephalus scirpaceus) eggs, over a period of 24 consecutive years. They found that ultraviolet-brownness of cuckoo eggs was similar to that of host eggs at parasitized nests but differed from that of host eggs at non-parasitized nests (Avilés et al. 2006). Subsequently, three short-term studies investigated the degree of cuckoo-host egg matching between parasitized and non-parasitized nests (Cherry et al. 2007; Antonov et al. 2012; Honza et al. 2014). Cherry et al. (2007) tested this hypothesis in the Great Reed Warbler (A. arundinaceus), while Antonov et al. (2012) conducted an experiment with the Mash Warbler (A. palustris).

Table 1 Summary of previous studies of egg matching by cuckoos and current theories violated by the findings

\begin{tabular}{|c|c|c|c|c|c|}
\hline Former studies & Data source & Method & Main findings & $\begin{array}{l}\text { Theories violated by the } \\
\text { findings }\end{array}$ & Costs for the cuckoos \\
\hline Avilés et al. (2006) & $\begin{array}{l}\text { Museum and } \\
\text { field data }\end{array}$ & \multirow{4}{*}{$\begin{array}{l}\text { comparing cuckoo egg } \\
\text { matching between } \\
\text { parasitized and } \\
\text { non-parasitized nests }\end{array}$} & $\begin{array}{l}\text { cuckoos laid } \\
\text { matching eggs }\end{array}$ & \multirow{3}{*}{$\begin{array}{l}\text { secretive behavior and rapid } \\
\text { egg-laying of cuckoos; host } \\
\text { imprinting and host selection } \\
\text { by cuckoos }\end{array}$} & \multirow{3}{*}{$\begin{array}{l}\text { increase the risk of detection } \\
\text { by hosts; loss of time searching } \\
\text { for nests and monitoring host } \\
\text { behavior; mis-imprinting in } \\
\text { host selection }\end{array}$} \\
\hline Cherry et al. (2007) & Field data & & $\begin{array}{l}\text { cuckoos laid } \\
\text { matching eggs }\end{array}$ & & \\
\hline Honza et al.(2014) & Field data & & $\begin{array}{l}\text { cuckoos laid } \\
\text { matching eggs }\end{array}$ & & \\
\hline Antonov et al. (2012) & Field data & & $\begin{array}{l}\text { cuckoo laid eggs } \\
\text { randomly }\end{array}$ & - & $\begin{array}{l}\text { waste of poor-matching eggs } \\
\text { in nests when hosts are good } \\
\text { rejecters }\end{array}$ \\
\hline
\end{tabular}


However, these two studies present opposing conclusions. A final study by Honza et al. (2014) of great reed warblers quantified egg color by relying on physiological modeling of avian color vision. They also assessed cuckoo egg matching in host clutches that were suitable for parasitism in terms of timing but remained non-parasitized (Honza et al. 2014). However, multi-parasitized nests were excluded from their study. A total of 19 nests (31\%) out of 61 nests were parasitized, while four nests (21\%) were double parasitized and hence not included in the analysis (Honza et al. 2014).

These empirical studies attempted to assign parasitism status correctly in order to avoid the idea that cuckoo eggs in some parasitized nests had been rejected by hosts before their detection. These efforts included marking host eggs in each nest soon after laying (Cherry et al. 2007, Honza et al. 2014) or using nests found during nest building or at early stages of egg laying (Antonov et al. 2012) (Table 1). All the same, the potential risk of undetected parasitism and rejection by hosts still exists, no matter how small. Logically, only real fulltime monitoring can completely exclude this bias. So far among these previous studies, Honza et al. (2014) have provided convincing support for solving this problem. However, they have not analyzed mimicry of egg pattern, which cannot be quantified by spectra. Recently new pattern quantification techniques from avian vision were developed (Stoddard and Stevens 2010; Stoddard et al. 2014), which may eliminate this restriction. Furthermore, since Common Cuckoos remove one host egg before laying their own egg (Davies 2000), scientists would be unable to compare the whole clutch of parasitized nests with that of non-parasitized nests, contributing further bias to studies. Such effects may be slight in host species with low intraclutch variation but can be severe in species with high intraclutch variation. To eliminate this problem, the spectra of each host egg should be measured soon after it is laid to avoid omission of any egg removal by cuckoos. Such frequent manipulation will exert considerable disturbance on both hosts and cuckoos, increase the rate of nest desertion of hosts and obstruct cuckoo parasitism, since cuckoos usually lay eggs during the egg-laying period of their hosts (Davies 2000). Moreover, such disturbance will also increase or decrease the risk of predation (Ibáñnz-Álamo et al. 2012). All these potential risks may together affect the results and cause bias. Additionally, none of these studies provide direct evidence of cuckoos choosing to parasitize host nests where egg color and pattern match. The degree of egg matching between cuckoo eggs and those of a host, as detected by humans, should be caused by egg recognition ability of hosts, rather than the selection of matching host eggs by cuckoos (Table 1 ).

\section{Secretive behavior and rapid egg-laying vs. laying eggs matching host eggs}

In order to deceive their hosts successfully, parasitic cuckoos have evolved a variety of tricks, selected for various anti-parasitic defences by hosts (Davies 2011). At first, female cuckoos should behave secretively to gain access to host nests for egg laying to avoid detection by hosts (Payne 1977). Detection, mobbing or attack by hosts are costly for cuckoos. Mobbing or attack by hosts may cause failure of egg-laying, injury and even have lethal consequence for adult cuckoos (Liversidge 1970; Davies 2000, 2011; Røskaft et al. 2002; Krüger 2011). For example, the mobbing by the bulbul (Pycnonotus capensis) makes it difficult for the female Jacobin cuckoo (Clamator jacobinus) to gain access to the host nest, but also difficult to monitor host behavior and hence time her laying correctly. In the end, many cuckoo eggs are laid too late and fail to hatch (Liversidge 1970; Krüger 2011). Furthermore, exposure, when laying eggs, also increases the rejection rate of cuckoo eggs because hosts may enhance their ability to discriminate against foreign eggs from increased risk of parasitism (e.g. Brooke et al. 1998; Stokke et al. 2008). Therefore, female cuckoos have evolved an astonishing ability of rapid egg-laying, i.e., in 7-158 seconds, a strong selection (evolutionary?) option as a consequence of nest defence by hosts (Payne 1977; Davies 2000; Moksnes et al. 2000). Fast egg laying in most obligate interspecific brood parasites is common and may have evolved to minimize host detection, which can elicit host defences and lower the likelihood of successful parasitism (Davies and Brooke Davies and Brooke 1988; Kattan 1997; Langmore et al. 2003; Mermoz and Reboreda 2003). Hosts can increase their defences when detecting parasite activity, which should select for cryptic habits in brood parasites (Moksnes et al. 1991; Bártol et al. 2003; Feeney et al. 2012).

However, when cuckoos search for host nests and lay eggs matching the appearance of the eggs of their hosts based on their own egg morphs, this will considerably increase the risk of detection by hosts because of high activity during parasitism. For example, a female Common Cuckoo of the parrotbill-specific gentes that lays blue eggs, should parasitize blue clutches of hosts. However, she cannot predict the color of host eggs before the female parrotbill lays them. Although parasitism generally occurs during the laying period, cuckoos spend most of their time monitoring the reproductive activity of their hosts (Davies 2000). Consequently, we can imagine that the blue-egg cuckoo would have to neglect white clutches that she has encountered and keep looking for blue clutches. That allows us to predict the costs for this phenomenon, for (1): this increases the risk of detection by hosts, which may cause subsequent attack or promote egg rejection by hosts (Moksnes et al. 1991; Honza et al. 2002) and (2): it causes loss of time seeking for host nests 
and monitoring host behavior (Table 1). The negative outcome of the second problem for cuckoos is undoubtedly costly for cuckoos invest time to search for host nests and monitor their breeding behavior within a breeding season (Chance 1940, Davies 2011). If the proportion of blue and white clutches in parrotbills is $1: 1$, female cuckoos face a probability of only $50 \%$ of the host egg color matching that of their own eggs. The real proportion of blue and white clutches in parrotbills is similar to this ratio (Yang et al. 2010).

Scientists may argue that laying eggs in a host nest randomly is also costly because of the waste of eggs in nests with poorly matching eggs. To compare the costs and benefits, we should consider nest density, habitat distribution of various egg morphs and the ability to recognize different host species in their habitat. We suggest that scientists should use mathematical modeling to quantify the costs of both properties and simulate the outcomes. In addition, egg laying by female cuckoos is so fast (less than 10 seconds, Davies 2000) that it could also prevent cuckoos from watching the host eggs carefully to check for matching status. Furthermore, so far no observation or video recording has shown that a female cuckoo gives up laying an egg in host nests when she finds that the host clutch does not match her egg morph, although some strange behavior of cuckoos, visiting host nests without laying eggs, has been recorded (Moksnes et al. 2000, Honza et al. 2002). Long-time monitoring, secretive approach and rapid egg laying by cuckoos are proven to be widespread and undoubted adaptations, selected by host defences (Rothstein and Robinson 1998; Davies 2000; Soler 2014). Matched egg laying with respect to egg phenotype contradicts these adaptations and thus seems to be maladaptive. One may argue that this inference is not persuasive. In the following we provide further arguments to show that cuckoo egg laying, based on the appearance of their own eggs, is maladaptive for host selection.

\section{Host selection and mis-imprinting}

Parasitic cuckoos can lay a variety of egg morphs to utilize different species of hosts. For example, common cuckoos in Europe have been divided into at least 16 host-specific races or gentes based on human visual inspection (Wyllie 1981; Álvarez 1994; Moksnes and Røskaft 1995). The question of how cuckoos maintain these distinct gentes and select hosts remains a puzzle (Honza et al. 2001). Two major hypotheses have been suggested - host imprinting and habitat imprinting (Lack 1968; Lotem 1993; Teuschl et al. 1998). The host imprint hypothesis assumes that a female cuckoo lays the same egg type as her mother and seeks to parasitize the same host species that raised her through imprinting on the characteristics of host parents (Lack 1968, Davies 2000). Therefore, for example, a female cuckoo nestling, raised by parrotbills, should choose to parasitize parrotbill nests when she starts to breed. For the habitat imprinting hypothesis, cuckoo nestlings imprint on the habitats in which they hatched (Moksnes and Røskaft 1995, Teuschl et al. 1998). Another explanation is a mixture of these two hypotheses with a sequence of decisions (Teuschl et al. 1998; Davies 2000). Scientists tend to believe that the most likely is host imprinting as shown for host choice by parasitic finches (Nicolai 1961; Davies 2000), although habitat imprinting may serve as a pre-adaptation for general nest searches by cuckoos (Teuschl et al. 1998, Honza et al. 2002, Vogl et al. 2002).

Natural selection acts on the phenotypes or the observable characteristics of organisms, which relate to fitness and vary between individuals within populations (Darwin 1859). Therefore, variation in egg phenotypes among individual cuckoos favors those that maximize fitness by utilizing potential new host species, especially when common hosts evolve high rates of egg rejection and cuckoos hence have low reproductive success in commonly parasitized nests compared to nests of novel hosts. For example, common cuckoos have been found to parasitize more than 300 species of hosts, which belong to about 46 families of birds (Lowther 2013).

We developed a conceptual and straightforward model to illustrate the outcome of potential host selection by cuckoos under two scenarios that reflect random egg laying or phenotypic matching (Figure 1). In this model we hypothesize that a female common cuckoo of the parrotbill gens lays a blue egg (female embryo inside) in a nest of a potential new, naive and suitable host by chance, which lays monomorphic white eggs. If accepted, the female cuckoo egg will hatch, while the host parents will rear the nestling. When this cuckoo chick successfully fledges, she returns to the place of hatching or disperses elsewhere, but chooses to parasitize the new host on which she has imprinted. If cuckoos lay eggs matching those of the hosts, based on their own egg appearance and if this behavior were inherited, this young female cuckoo would lay blue eggs. Thus we can speculate that the reproductive success of this young female cuckoo is zero because she can never find any nest in which the egg color matches her own. Even if imprinting of egg appearance in cuckoos (i.e., knowing their own egg appearance) is acquired through learning rather than inherited, this female cuckoo can only succeed in her first trial of laying for learning, but again fails to find any suitable nest for the rest of her life. By contrast, if cuckoos utilize hosts by laying eggs randomly, they will enjoy greater reproductive success (Figure 2). Therefore, there is a risk of mis-imprinting when cuckoos lay eggs based on the appearance of their own eggs. We also consider additional situations in the model (see Figures 1 and 2 for more details), which are interpreted below. 


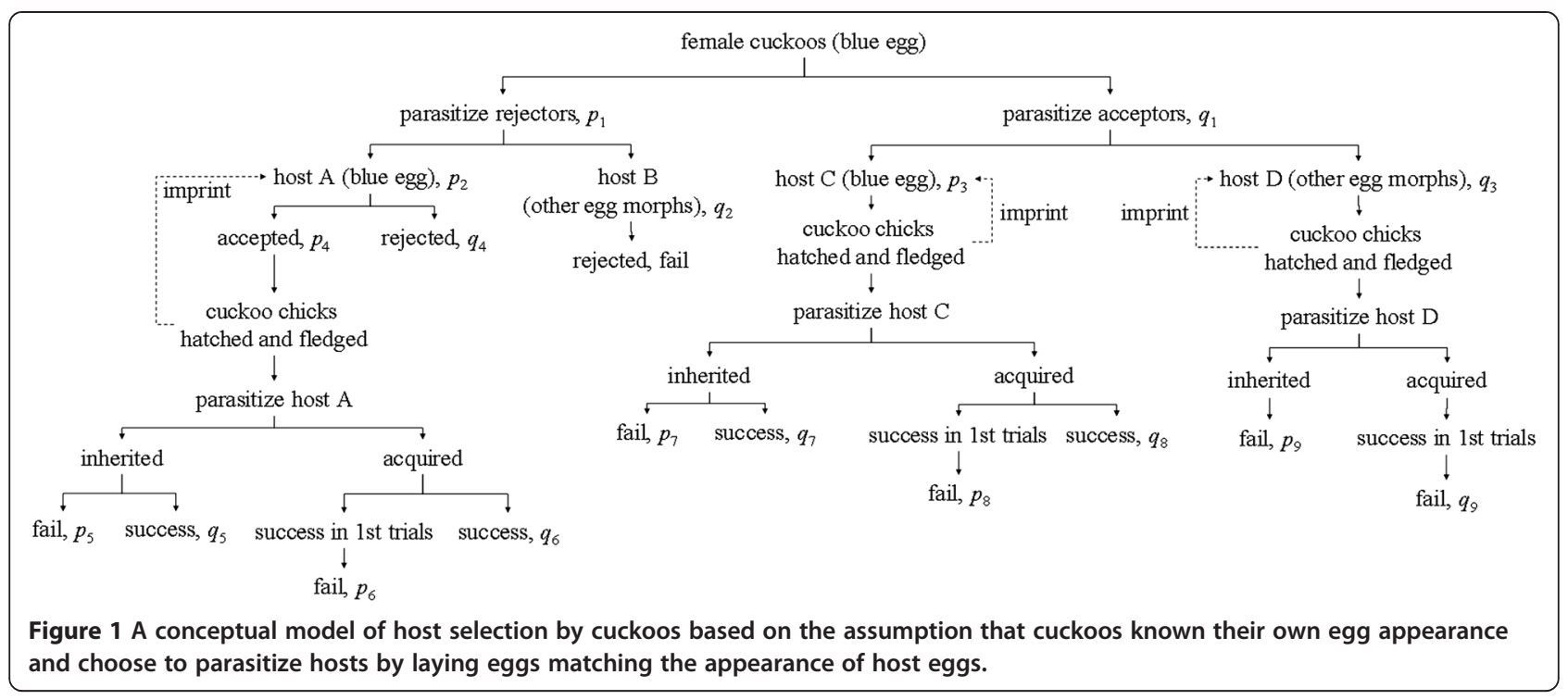

\section{Conceptual model of host shift based on different egg-laying behavior}

Our conceptual model is based on the assumptions that (1): rejectors refer to hosts that reject all non-mimetic eggs and acceptors that accept them, (2): the new host species lays blue eggs, which are similar to the blue cuckoo eggs, but not particularly matching because it has had no coevolutionary history with the cuckoo, hence blue egg rejectors of hosts also reject a proportion of blue cuckoo eggs and (3): the cuckoo chicks imprint on the host species, which raise them.

According to Figure 1, female cuckoos have a probabilities of $p_{1}$ to parasitize hosts of rejectors and and $q_{1}$ of acceptors, where $p_{1}+q_{1}=1$. Rejectors then can be divided into hosts laying eggs of different appearance, including blue eggs (host A with $p_{2}$ ), which are similar to those of the female cuckoos and other egg morphs (host B with $q_{2}$ ). However, host B rejects all blue eggs and causes failure of cuckoo parasitism. Host A accepts a proportion $\left(p_{4}\right)$ of blue cuckoo eggs, but rejects the others $\left(q_{4}\right)$. Only the accepted blue eggs can be incubated by hosts resulting in the cuckoo chicks fledging and choosing to parasitize host A again, with the consequence that the cuckoo chick has a probability of success of $q_{5}$ and $q_{6}$ to coevolve with host A. According to the second assumption, this probability $\left(q_{5}+q_{6}\right)$ depends on the eggmatching abilities of female cuckoos. In other words, $q_{5}$ and $q_{6}$ decreases with the increasing egg-matching ability of female cuckoos. This is close to zero when cuckoos have a good ability to match the egg appearance of hosts during laying. We included two mechanisms of acquisition of information on the appearance of own eggs in cuckoos in the model. However, even if the ability of learning egg appearance in cuckoos is acquired rather than inherited, female cuckoos can only succeed in their first trials of laying for learning but fail the second time. Similarly, for acceptor hosts laying blue eggs, female cuckoos possess a success rate of $q_{7}$ and $q_{8}$, which also decrease with the increase of egg-matching ability by cuckoos. In short, a successful probability is the sum of $p_{5}+p_{6}+p_{7}+p_{8}$, which is close to zero when cuckoos have a great ability to lay eggs with a high degree of egg matching. In such a situation

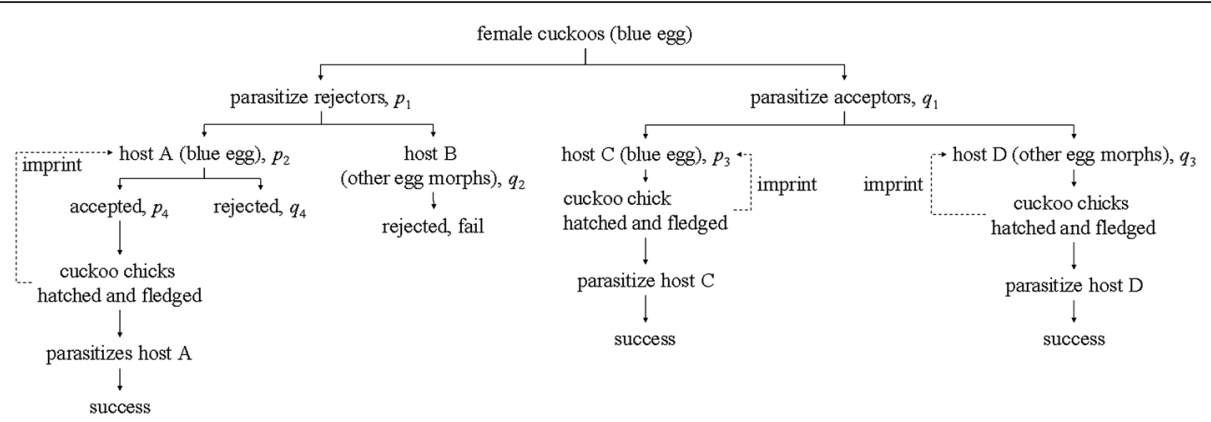

Figure 2 A conceptual model of host selection by cuckoos based on the assumption that cuckoos choose to parasitize hosts by laying eggs randomly in host nests. 
almost no cuckoo offspring can succeed in utilizing new host species.

By contrast, the results from the model that cuckoos parasitize new host species by laying eggs randomly are much simpler (Figure 2). Only if the new hosts were rejectors and laid non-blue eggs would this cause failure of cuckoo parasitism.

\section{Conclusions}

We have argued theoretically that laying eggs matching those of the host, violates the key traits in the life history of cuckoos and therefore should not evolve by natural selection.

First, egg matching behavior is against the secretive behavior of approaching cuckoos near host nests and wastes time by long-term monitoring of host behavior on the part of cuckoos.

Second, if cuckoos chose hosts with eggs similar to those with their own egg appearance, they would cause extreme constraints on the flexibility of their offspring to accept and adapt to a new host by pushing them into an evolutionary dead-end. Therefore, this would entirely cut off the evolution of exploitation of new hosts. It is likely that the percentage of egg matching between cuckoo and host eggs, as detected by humans, should be caused by the ability of egg recognition on the part of hosts (Davies and Brooke 1989), rather than the selection of matching host eggs by cuckoos.

Finally, we suggest an empirical method, referred to as an "induced parasitism experiment", that may provide direct evidence to demonstrate how the cuckoo lays its eggs. In such an experiment, scientists establish artificial nests in which eggs of a different appearance are provided for egg laying by cuckoos. In this scenario, female cuckoos can readily monitor the focal nests because of the short distances between nests and lay an egg randomly or match the egg appearance of the eggs in these nests with that of their own eggs. If female cuckoos do not match their eggs with those of their hosts in this scenario of little or no constraints, there is no reason to believe that female cuckoos would be able to achieve a greater level of matching under natural conditions when host nests are considerably more difficult to find. This method should be feasible because Chance (1940) actually carried out a similar trial_before, collecting cuckoo eggs.

We conclude by suggesting that cuckoo egg laying by matching host eggs is maladaptive and should not evolve from natural selection.

\section{Competing interests}

The authors declare that they have no competing interests.

\section{Authors' contributions}

WL designed the study. FT, WL and CY discussed and developed the modeling and $C Y$ performed all analyses. CY and AP drafted the manuscript. All authors have read and approved the final version of the paper.

\section{Acknowledgements}

This work was funded by the National Natural Science Foundation of China (nos. 31071938, 31272328 and 31472013 to WL, and 31260514 to CY), the Program for New Century Excellent Talents in University (NCET-13-0761), the Key Project of the Chinese Ministry of Education (no. 212136) and the Program of International S \& T Cooperation (KJHZ2013-12) to CY.

\section{Author details}

${ }^{1}$ Ministry of Education Key Laboratory for Tropical Plant and Animal Ecology, College of Life Sciences, Hainan Normal University, Haikou 571158, China.

${ }^{2}$ Department of Information and Computer Sciences, Nara Women's University, Kita-Uoya Nishimachi, Nara 630-8506, Japan. ${ }^{3}$ Laboratoire d'Ecologie, Systématique et Evolution, CNRS UMR 8079, Université Paris-Sud, Orsay Cedex F-91405, France.

Received: 7 October 2014 Accepted: 2 February 2015

Published online: 01 April 2015

\section{References}

Álvarez F (1994) A gens of cuckoo Cuculus canorus parasitizing rufous bush chat Cercotrichas galactotes. J Avian Biol 25:239-243

Antonov A, Stokke BG, Fossøy F, Ranke PS, Liang W, Yang C, Moksnes A, Shykoff $J$, Røskaft E (2012) Are cuckoos maximizing egg mimicry by selecting host individuals with better matching egg phenotypes? PLoS One 7:e31704

Avilés JM, Stokke BG, Moksnes A, Røskaft E, Åsmul M, Møller AP (2006) Rapid increase in cuckoo egg matching in a recently parasitized reed warbler population. J Evol Biol 19:1901-1910

Bártol I, Karcza Z, Moskát C, Røskaft E, Kisbenedek T (2003) Response of greed reed warblers Acrocephalus arundinaceus to experimental brood parasitism: the effects of a cuckoo Cuculus canorus dummy and egg mimicry. J Avian Biol 33:420-425

Brooke M d L, Davies NB (1988) Egg mimicry of cuckoos Cuculus canorus in relation to discrimination by hosts. Nature 335:630-632

Brooke ML, Davies NB, Noble DG (1998) Rapid decline of host defences in response to reduced cuckoo parasitism: behavioural flexibility of reed warblers in a changing world. Proc R Soc Lond B 265:1277-1282

Chance EP (1940) The Truth about the Cuckoo. Country Life, London

Cherry MI, Bennett ATD, Moskát C (2007) Do cuckoos choose nests of great reed warblers on the basis of host egg appearance? J Evol Biol 20:1218-1222

Darwin C (1859) The Origin of Species. John Murray, London

Davies NB (2000) Cuckoos. Cowbirds and Other cheats. T \& AD Poyser, London

Davies NB (2011) Cuckoo adaptations: trickery and tuning. J Zool 284:1-14

Davies NB, Brooke M d L (1988) Cuckoos versus reed warblers: adaptations and counteradaptations. Anim Behav 36:262-284

Davies NB, Brooke ML (1989) An experimental study of co-evolution between the cuckoo Cuculus canorus and its hosts. I. Host egg discrimination. J Anim Ecol 58:207-224

Dawkins R, Krebs JR (1979) Arms races between and within species. Proc R Soc Lond B 205:489-511

Feeney WE, Welbergen JA, Langmore NE (2012) The frontline of avian brood parasite-host coevolution. Anim Behav 84:3-12

Honza M, Moksnes A, Røskaft E, Stokke BG (2001) How are different common cuckoo Cuculus canorus egg morphs maintained? An evaluation of different hypotheses. Ardea 89:341-352

Honza M, Taborsky B, Taborsky M, Teuschl Y, Vogl W, Moksnes A, Røskaft E (2002) Behaviour of female common cuckoos, Cuculus canorus, in the vicinity of host nests before and during egg laying: a radiotelemetry study. Anim Behav 64:861-868

Honza M, Šulc M, Jelínek V, Požgayová M, Procházka P (2014) Brood parasites lay eggs matching the appearance of host clutches. Proc R Soc Lond B 281:20132665

Ibáñnz-Álamo JD, Sanllorente O, Soler M (2012) The impact of researcher disturbance on nest predation rates: a meta-analysis. Ibis 154:5-14

Jenner E (1788) Observations on the natural history of the cuckoo. Phil Trans R Soc Lond 78:219-237

Kattan GH (1997) Shiny cowbirds follow the 'shotgun' strategy of brood parasitism. Anim Behav 53:647-654

Kilner RM (2006) The evolution of egg colour and patterning in birds. Biol Rev 81:383-406

Krüger O (2011) Brood parasitism selects for no defence in acuckoo host. Proc $R$ Soc Lond B 278:2777-2783 
Lack D (1968) Ecological Adaptations for Breeding in Birds. Methuen, London

Langmore NE, Hunt S, Kilner RM (2003) Escalation of a co-evolutionary arms race through host rejection of brood parasitic young. Nature 422:157-160

Lee $Y$ (2008) Egg discrimination by the vinous-throated parrotbill, a host of the common cuckoo that lays polychromatic eggs. MSc thesis. University of Manitoba, Canada

Liversidge R (1970) The biology of the Jacobin cuckoo Clamator jacobinus. Ostrich (Suppl) 8:117-137

Lotem A (1993) Learning to recognize nestling is maladaptive for cuckoo Cuculus canorus hosts. Nature 362:743-744

Lowther PE (2013) Host List of Avian Brood Parasitism. Field Museum, Chicago, IL

Mermoz ME, Reboreda JC (2003) Reproductive success of shiny cowbird (Molothrus bonariensis) parasitizing the larger brown-and-yellow marshbird (Pseudoleistes virescens) in Argentina. Auk 120:1128-1139

Moksnes A, Røskaft E (1995) Egg-morphs and host preference in the common cuckoo (Cuculus canorus): ananalysis of cuckoo and host eggs from European museum collections. J Zool 236:625-648

Moksnes A, Røskaft E, Braa AT (1991) Rejection behaviour by common cuckoo hosts towards artificial brood parasitic eggs. Auk 108:348-354

Moksnes A, Røskaft E, Hagen LG, Honza M, Mørk C, Olsen PH (2000) Common cuckoo Cuculus canorus and host behaviour at reed warbler Acrocephalus scirpaceus nests. Ibis 142:247-258

Nicolai J (1961) Die Stimmen Einiger Viduinen. J für Ornithol 102:213-214

Payne RB (1977) The ecology of brood parasitism in birds. Ann Rev Ecol Syst 8:1-28

Payne RB (2005) The Cuckoos. Oxford University Press, Oxford

Peck AL (1970) Aristotle: Historia Animalium. Heinemann, Longdon

Røskaft E, Moksnes A, Stokke BG, Bicik V, Moskát C (2002) Aggression to dummy cuckoos by potential European cuckoo hosts. Behaviour 139:613-628

Rothstein SI, Robinson SK (1998) Parasitic Birds and Their Hosts: Studies in Coevolution. Oxford University Press, Oxford

Soler M (2014) Long-term coevolution between avian brood parasites and their hosts. Biol Rev 89:688-704

Stoddard MC, Stevens M (2010) Pattern mimicry of host eggs by the common cuckoo, as seen through a bird's eye. Proc R Soc B 277:1387-1393

Stoddard MC, Kilner MR, Tow C (2014) Pattern recognitioin algorithm reveals evolve individual egg pattern signature. Nature Communicat. doi: 10.1038/ncomms5117

Stokke BG, Hafstad I, Rudolfsen G, Moksnes A, Møller AP, Røskaft E, Soler M (2008) Predictors of resistance to brood parasitism within and among reed warbler populations. Behav Ecol 19:612-620

Teuschl Y, Taborsky B, Taborsky M (1998) How do cuckoos find their hosts? The role of habitat imprint. Anim Behav 56:1425-1433

Vogl W, Taborsky M, Toborsky B, Teuschl Y, Honza M (2002) Cuckoo females preferentially use specific habitats when searching for host nests. Anim Behav 64:843-850

Wyllie I (1981) The Cuckoo. Batsford, London

Yang C, Liang W, Cai Y, Shi S, Takasu F, Møller AP, Antonov A, Fossøy F, Moksnes A, Røskaft E, Stokke BG (2010) Coevolution in action: Disruptive selection on egg colour in an avian brood parasite and its host. PLoS One 5:e10816

Yang C, Antonov A, Cai Y, Stokke BG, Moksens A, Røskaft E, Liang W (2012a) Large hawk-cuckoo Hierococcyx sparverioides parasitism on the Chinese babax Babax lanceolatus may be an evolutionarily recent host-parasite system. Ibis 154:200-204

Yang C, Liang W, Antonov A, Cai Y, Stokke BG, Fossøy F, Moksnes A, Røskaft E (2012b) Diversity of parasitic cuckoos and their hosts in China. Chinese Birds 3:9-32

Yang C, Cai Y, Liang W (2013a) Egg mimicry of common cuckoo (Cuculus canorus) utilizing ashy-throated parrotbill (Paradoxornis alphonsianus) host. Chinese Birds 4:51-56

Yang C, Stokke BG, Antonov A, Cai Y, Shi S, Moksnes A, Røskaft E, Møller AP, Liang W, Grim T (2013b) Host selection in parasitic birds: are open-cup nesting insectivorous passerines always suitable cuckoo hosts? J Avian Biol 44:216-220

\section{Submit your next manuscript to BioMed Central and take full advantage of:}

- Convenient online submission

- Thorough peer review

- No space constraints or color figure charges

- Immediate publication on acceptance

- Inclusion in PubMed, CAS, Scopus and Google Scholar

- Research which is freely available for redistribution 